\section{Surgical treatment in nystagmus}

\begin{abstract}
Purpose To evaluate the effect of symmetric recession surgery on all four horizontal rectus muscles in the treatment of patients with congenital motor nystagmus and sensory nystagmus secondary to albinism, dyschromatopsia and degenerative myopia. Methods Prospectively, four patients with a diagnosis of congenital motor nystagmus and eight patients with sensory nystagmus were operated on. The amount of recession was determined according to the ocular alignment of the patients. Electronystagmographic recordings were conducted in every patient pre-operatively and post-operatively, as well as an ophthalmological examination.
\end{abstract}

Results Mean age of the patients at the time of the first visit was $6.7 \pm 4.2$ years (range 9 months to 14 years) and mean age at the time of operation was $8.3 \pm 2.7$ years (range 6-14 years). In 8 cases an equal amount of weakening of the four horizontal recti was done, whereas in $\mathbf{2}$ cases more recession on the lateral recti due to exotropia and in 2 cases more recession on the medial recti due to esotropia was performed. Mean follow-up time was 15.8 months (min. 6 months, max. 28 months). Improvement in visual function was achieved in 7 patients. Amplitude decreased in 9 patients. One patient had a decrease in visual acuity due to progression of her primary macular degeneration. Improvement in head posture was seen in 3 patients and there was no change in the head posture in 2 patients. One patient acquired head posture after surgery. Restriction of motility was seen in none of the patients after surgery in spite of large amounts of recession. Recession of horizontal recti decreased nystagmus amplitude and frequency in $81.8 \%$ of patients. Improvement in visual function, measured as an increase in visual acuity in terms of Snellen lines, was achieved in $63.6 \%$ of patients. Conclusion Symmetric recession of the horizontal rectus muscles is shown to be a successful procedure to perform in nystagmus patients, resulting in an increase in visual acuity and a decrease in nystagmus amplitude and frequency. It is a reliable alternative to the Kestenbaum operation and is easier to perform surgically.
HUBAN ATILLA, NECILE ERKAM, YUSUF IŞIKÇELIK
Key words Congenital motor nystagmus, Sensory nystagmus, Surgery

Nystagmus is the second most common paediatric ocular motor disorder following strabismus. ${ }^{1}$ The initial description of attempted treatment of congenital nystagmus was reported by Metzger, who placed prisms before the eyes of patients with nystagmus. Other treatment modalities such as minus lenses, pharmacological agents and botulinum toxin injection have all been described in different studies. ${ }^{2-8}$ In 1953, Kestenbaum recommended surgical shifting of the eyes by identical amounts of recession and resection, in the direction of the rapid phase of nystagmus away from the null point. ${ }^{9}$ Later, Anderson and Goto, followed by Parks, Calhoun and Nelson, reported the results of different surgical procedures to correct head postures. ${ }^{10,11}$ The Faden operation was also added to standard or modified Kestenbaum surgeries. ${ }^{12,13}$

Surgery in nystagmus is usually performed to correct head posture and to improve vision by decreasing the amplitude or frequency of nystagmus. ${ }^{14,15}$ Symmetric, large recti recessions were first introduced by Bietti and Bagolini, later reintroduced by Limon and Bernadeli, and recently gained popularity following the studies of von Noorden and Sprunger and of Helveston et al. ${ }^{16,17}$ In this study, we tried to evaluate the efficacy of this type of surgery with objective measurements using pre-operative and post-operative electronystagmography recordings, and compared the results for sensory and motor nystagmus groups.

\section{Materials and methods}

Twelve nystagmus patients seen in the paediatric ophthalmology department were included in this prospective study. Surgery was performed after 6 years of age in all patients. A minimum follow-up period of 6 months after surgery was required as an inclusion criterion. Visual acuity measurements (both corrected and uncorrected), slit lamp examination, fundus examination, motility and alignment measurements, fusion with the Worth 4-dot test and stereopsis with the Titmus test were
H. Atilla

N. Erkam

Y. Işikçelik

Department of

Ophthalmology School of Medicine

Ankara University

Ankara, Turkey

Huban Atilla, MD Mahatma Gandi cad Mesa-Ufuk 1 51/17 06700 GOP Ankara Turkey

Tel: +90 3124462345 Fax: +903124680094 e-mail: satilla@bir.net.tr

This study was presented at the XIth European Ophthalmology meeting in Budapest, June 1997

Received: 20 April 1998 Accepted in revised form: 30 November 1998 
Table 1. Age at the time of first admission, onset and operation, sex, diagnosis of patients and the amount of surgery

\begin{tabular}{|c|c|c|c|c|}
\hline $\begin{array}{l}\text { Case no./ } \\
\text { Sex/Age (years) }\end{array}$ & Diagnosis & Age of onset & $\begin{array}{l}\text { Age at } \\
\text { operation (years) }\end{array}$ & Operation (recession) \\
\hline $1 / F / 8$ & $\mathrm{CMN}$ & Birth & 7 & $\mathrm{MR}+\mathrm{LR} 10 \mathrm{~mm}$ \\
\hline $2 / \mathrm{M} / 5$ & CMN & 1 month & 6 & $\mathrm{MR} 8 \mathrm{~mm}+\mathrm{LR} 10 \mathrm{~mm}$ \\
\hline $3 / \mathrm{M} / 9$ & CMN & Birth & 10 & $\mathrm{MR}+\mathrm{LR} 10 \mathrm{~mm}$ \\
\hline $4 / F / 12$ & $\mathrm{CMN}$ & Birth & 13 & $\mathrm{MR}+\mathrm{LR} 10 \mathrm{~mm}$ \\
\hline $5 / \mathrm{M} / 8$ & Sensory (dyschromatopsia) & 2 years & 8 & $\mathrm{MR}+\mathrm{LR} 10 \mathrm{~mm}$ \\
\hline $6 / \mathrm{M} / 7$ & Sensory (dyschromatopsia) & Birth & 7 & $\mathrm{MR} 10 \mathrm{~mm}+\mathrm{LR} 8 \mathrm{~mm}$ \\
\hline $7 / \mathrm{M} / 6$ & Sensory (ocular albinism) & Birth & 7 & $\mathrm{MR}+\mathrm{LR} 10 \mathrm{~mm}$ \\
\hline $8 / \mathrm{M} / 7$ & Sensory (ocular albinism) & 6 months & 7 & $\mathrm{MR}+\mathrm{LR} 10 \mathrm{~mm}$ \\
\hline $9 / \mathrm{M} / 8$ & Sensory (ocular albinism) & 18 months & 8 & $\mathrm{MR}+\mathrm{LR} 10 \mathrm{~mm}$ \\
\hline $10 / \mathrm{M} / 6$ & Sensory (ocular albinism) & Birth & 6 & $\mathrm{MR} 10 \mathrm{~mm}+\mathrm{LR} 8 \mathrm{~mm}$ \\
\hline $11 / \mathrm{M} / 14$ & Sensory (degenerative myopia) & Birth & 14 & $\mathrm{MR}+\mathrm{LR} 10 \mathrm{~mm}$ \\
\hline $12 / F / 8$ & Sensory (ocular albinism) & 12 months & 8 & $\mathrm{MR} 7 \mathrm{~mm}+\mathrm{LR} 10 \mathrm{~mm}$ \\
\hline
\end{tabular}

CMN, congenital motor nystagmus; $\mathrm{MR}$, medial recti; LR, lateral recti.

performed in every patient. Electronystagmographic recordings were done by the same technician in the same laboratory before and 3 months after surgery. Patients were asked to fixate on a distant target (approximately $3 \mathrm{~m}$ ) during recordings. The amplitude of the nystagmus (degrees) was defined as the peak-to-peak slow phase displacement, frequency was defined as the number of oscillations per second (oscillations/s), and intensity (deg/s) was defined as the product of amplitude and frequency. Besides objective measurements with electronystagmography, subjective results were obtained by asking patients and parents about their feelings and observations related to the surgery.

Head posture measurements were done by having the patient fixate on a target (small toy about $20 \mathrm{~cm}$ high, placed $2 \mathrm{~m}$ away from the patient) and measuring the angle between the target and head deviation with an orthopaedic ruler. All surgeries were done by the same surgeon, with the patient under general anaesthesia. Recessed muscle was reattached to the post-equatorial sclera. In the post-operative period, steroid drops (prednisolone acetate q.i.d.) and antibiotic ointments (bacitracin b.i.d.) were prescribed for 10 days. Patients were examined post-operatively at the first day, first week, and first, third and sixth months and followed up at 6 month intervals. Pre-operative visual acuities, fusion and deviation measurements were compared with the post-operative values at the last visit, whereas preoperative electronystagmographic measurements were compared with post-operative recordings at the third month.

Diagnosis, age and sex characteristics of the patients are shown in Table 1. Mean age of the patients at the time of first visit was $6.7 \pm 4.2$ years (min. 9 months, max. 14 years), and mean age at the time the nystagmus was first noticed by the parents was $0.6 \pm 1.0$ years (min. birth, max. 2.5 years).

According to the ocular alignment, 8 patients were orthophoric and in these patients equal amounts of recession were done on all four horizontal recti. More recession on the medial recti $(10 \mathrm{~mm})$ than lateral recti $(8 \mathrm{~mm})$ were performed on two esotropia patients (25-30 PD ET). On two exotropia patients (20-30 PD XT), more recession on the lateral recti $(10 \mathrm{~mm})$ than medial recti
(7-8 mm) were done (Table 1). Orthophoria or 8-10 PD ET success rate was achieved in esotropia cases. In 2 exotropia patients, 1 had 14 PD intermittent exotropia post-operatively, and the other had 20-25 PD intermittent exotropia. Both had better control at near. One of the 8 patients with orthophoria pre-operatively had 12 PD exotropia post-operatively and still achieved fusion and a good level of stereopsis.

Wilcoxon matched pairs and Mann-Whitney $U$-tests were performed for statistical analysis.

\section{Results}

Four of the patients were diagnosed as having congenital motor nystagmus (CMN), while 8 patients had sensory nystagmus (5 patients had ocular/oculocutaneous albinism, 2 had dyschromatopsia, and 1 had degenerative myopia). Mean age of the patients at the time of surgery was $8.3 \pm 2.7$ years (min. 6, max. 14 years). Mean follow-up time was 15.8 months (min. 6 months, max. 28 months). Improvement in head posture, measured as a decrease in the amount of head turn, was seen in 3 patients. There was no change in head position in 2 patients and 1 patient acquired head posture after surgery that was not present previously. Restriction of motility was seen in none of the patients after surgery in spite of the large amounts of recession.

Visual acuity (VA) measurements improved in 8 patients, the increase in Snellen lines ranging from 1 to 3 lines. When we divided the patients into two groups according to whether they had CMN (group 1) or sensory nystagmus (group 2), mean VA was $0.44 \pm 0.09$ in group 1 and $0.16 \pm 0.09$ in group 2 before surgery. Mean VA after surgery was $0.66 \pm 0.11$ in group 1 and $0.22 \pm 0.14$ in group 2 . There was a statistically significant difference between the pre-operative and post-operative VAs in both groups $(p<0.001)$ (Table 2). When we compared the two groups in terms of Snellen line difference, the increase of VA was higher in group 1 $(p=0.0022, p<0.01)$.

When the pre-operative and post-operative binocular VAs were compared, there was an increase in 9 patients, a decrease in 1 patient and no change in 2 patients. The difference between the pre-operative and post-operative 
Table 2. Pre-operative and post-operative visual acuity (VA) of patients

\begin{tabular}{lccc}
\hline Case no. & Pre-operative $\mathrm{VA}^{\mathrm{a}}$ & Post-operative $\mathrm{VA}^{\mathrm{a}}$ & Difference \\
\hline 1 & 0.5 & 0.8 & +3 \\
& 0.5 & 0.6 & +1 \\
2 & 0.3 & 0.6 & +3 \\
& 0.4 & 0.6 & +2 \\
3 & 0.3 & 0.5 & +2 \\
& 0.5 & 0.6 & +1 \\
4 & 0.5 & 0.8 & +3 \\
& 0.5 & 0.8 & +3 \\
5 & 0.1 & 0.1 & - \\
& 0.1 & 0.1 & - \\
6 & 0.1 & 0.3 & +2 \\
& 0.1 & 0.3 & +2 \\
7 & 0.05 & 0.1 & +0.5 \\
& 0.05 & 0.1 & +0.5 \\
8 & 0.2 & 0.2 & - \\
& 0.2 & 0.2 & - \\
9 & 0.3 & 0.3 & - \\
& 0.3 & 0.5 & +2 \\
10 & 0.1 & 0.2 & +1 \\
& 0.1 & 0.2 & +1 \\
11 & 0.3 & 0.4 & +1 \\
& 0.3 & 0.4 & +1 \\
12 & 0.1 & 0.05 & -0.5 \\
& 0.1 & 0.05 & -0.5 \\
\hline
\end{tabular}

${ }^{a}$ In each case the value for the right eye is given first.

binocular VA was statistically significant $(p=0.0069$, $p<0.01$ ). The mean difference in group 1 was $0.4 \pm 0.08$ Snellen lines and in group 2, $0.13 \pm 0.13$ Snellen lines. The difference between the two groups was statistically significant $(p=0.0242, p<0.05)$. However, when we compare the binocular VA differences in terms of percentage (post-operative binocular VA-pre-operative binocular VA/pre-operative binocular), the difference was not statistically significant $(p=0.3152, p>0.05)$. The overall increase in binocular VA was $71.8 \%$ (85\% in group 1, 64.3\% in group 2).

The mean amplitude of nystagmus was $7.8 \pm 2.9 \mathrm{deg}$ (range 3.4-14.1) pre-operatively and $3.9 \pm 2.4$ deg (range 1.3-8.0) post-operatively. The amplitude of nystagmus pre-operatively was higher than the post-operative values and the difference was statistically significant $(p=0.0033, p<0.01)$. There was a decrease in amplitude in all patients (Table 3 ).
Table 4. Pre-operative and post-operative fusion status of patients and their final stereopsis values at the final post-operative visit

\begin{tabular}{lccc}
\hline Case no. & $\begin{array}{c}\text { Pre-operative } \\
\text { fusion }\end{array}$ & $\begin{array}{c}\text { Post-operative } \\
\text { fusion }\end{array}$ & $\begin{array}{c}\text { Stereopsis } \\
\text { (sec arc) }\end{array}$ \\
\hline 1 & $?$ & + & 400 \\
2 & + & + & 100 \\
3 & + & + & 60 \\
4 & + & + & 50 \\
5 & - & + & 800 \\
6 & - & + & 800 \\
7 & $?$ & - & 3000 \\
8 & + & + & 200 \\
9 & + & + & 100 \\
10 & + & + & 3000 \\
11 & + & + & 100 \\
12 & - & - & 3000 \\
& & & Mean: $940.8 \mathrm{sec}$ arc \\
\hline
\end{tabular}

Fusion was tested by the Worth 4-dot test and stereopsis by the Titmus test.

The pre-operative nystagmus frequency was $3.9 \pm 1.5$ oscillations/s (range 2.0-6.7), which changed to $3.5 \pm 1.3$ oscillations/s (range 1.7-5.5) post-operatively. The difference was statistically significant $(p=0.0342$, $p<0.05)$. Frequency of nystagmus in the post-operative period was lower in 9 patients and higher in 3 patients (Table 3).

The intensity of nystagmus (obtained as the product of frequency and amplitude) showed a decrease in the post-operative period and this decrease was statistically significant $(z=-3.059, p<0.01)$. Mean pre-operative intensity was $28.9 \pm 11.3 \mathrm{deg} / \mathrm{s}$ (range 12.8-48.2), which changed post-operatively to $12.7 \pm 6.3 \mathrm{deg} / \mathrm{s}$ (range 5.8-24.6) (Table 3).

On evaluation of the difference in sensory status, almost all patients in the CMN group had pre-operative and post-operative fusion with the Worth 4-dot test. However, in the sensory nystagmus group, half the patients had pre-operative and post-operative fusion, 2 had no fusion at all and 2 patients were able to fuse after surgery. CMN patients had better stereopsis values (Table 4).

Table 3. Pre-operative and post-operative measurements of nystagmus amplitude, frequency and intensity

\begin{tabular}{|c|c|c|c|c|c|c|}
\hline Case no. & $\begin{array}{c}\text { Pre-operative } \\
\text { amplitude (deg) }\end{array}$ & $\begin{array}{l}\text { Post-operative } \\
\text { amplitude (deg) }\end{array}$ & $\begin{array}{c}\text { Pre-operative } \\
\text { frequency (osc/s) }\end{array}$ & $\begin{array}{c}\text { Post-operative } \\
\text { frequency (osc/s) }\end{array}$ & $\begin{array}{c}\text { Pre-operative } \\
\text { intensity }(\mathrm{deg} / \mathrm{s})\end{array}$ & $\begin{array}{l}\text { Post-operative } \\
\text { intensity (deg/s) }\end{array}$ \\
\hline 1 & 7.2 & 1.3 & 6.7 & 5.5 & 48.2 & 7.2 \\
\hline 2 & 11.0 & 3.4 & 2.0 & 1.7 & 22.0 & 5.8 \\
\hline 3 & 4.0 & 2.0 & 3.2 & 4.1 & 12.8 & 8.2 \\
\hline 4 & 7.5 & 3.0 & 3.1 & 2.9 & 23.3 & 8.7 \\
\hline 5 & 9.0 & 5.0 & 3.0 & 3.1 & 27.0 & 15.5 \\
\hline 6 & 8.0 & 4.6 & 2.2 & 1.7 & 17.6 & 7.8 \\
\hline 7 & 14.1 & 8.0 & 3.3 & 2.3 & 46.5 & 18.4 \\
\hline 8 & 8.0 & 6.0 & 5.0 & 4.1 & 40.0 & 24.6 \\
\hline 9 & 6.5 & 2.0 & 5.0 & 4.1 & 32.5 & 8.2 \\
\hline 10 & 9.0 & 7.0 & 3.0 & 3.1 & 27.0 & 21.7 \\
\hline 11 & 6.0 & 3.5 & 5.2 & 4.6 & 31.2 & 16.1 \\
\hline 12 & 3.4 & 2.0 & 5.6 & 5.2 & 19.0 & 10.4 \\
\hline Mean & $7.8 \pm 2.9$ & $3.9 \pm 2.4$ & $3.9 \pm 1.5$ & $3.5 \pm 1.3$ & $28.9 \pm 11.3$ & $12.7 \pm 6.3$ \\
\hline
\end{tabular}


When questions regarding the feelings of patients and parents about surgery were asked, $83 \%$ (10 patients) stated they had better control of nystagmus postoperatively.

\section{Discussion}

Nystagmus in infancy may be present at birth but more frequently appears in the first 6 months of life and can be classified as follows: latent nystagmus, congenital motor nystagmus (CMN), sensory defect nystagmus and nystagmus associated with neurological disease. Typical $\mathrm{CMN}$ is conjugate and horizontal. A completely normal child presenting with typical CMN, visual acuity of 0.3 or better, and no other neurological or ocular defects can be diagnosed as having CMN without further investigations. ${ }^{18}$ Patients appear to have clinically normal visual sensory systems; however, recent studies with visual evoked potentials suggest that these patients may have aberrantly crossed inputs to the visual cortex. ${ }^{19}$

Sensory defect nystagmus is the most common form of congenital nystagmus after latent nystagmus and is secondary to a variety of obvious or subtle disorders such as albinism, cataracts, corneal opacities, optic disc atrophy and developmental disorders of the optic disc and retina. ${ }^{20}$ Sensory defects are usually present in the congenital nystagmus group in up to $82-91 \%$ of patients. $^{18}$

Decreased foveation time and image movement are the possible factors responsible for reduced vision and amblyopia. ${ }^{21}$ In nystagmus, reducing eye oscillations is suggested to increase foveation time, reduce movement of image on the retina and improve vision. Because of this, many patients assume a specific head posture for better vision at a null or neutral point to decrease nystagmus. Convergence is another strategy that results in improved vision. ${ }^{17}$ In treatment of nystagmus, decreasing the amplitude and frequency of nystagmus to increase foveation time and visual acuity is the main aim. For this purpose, many different treatment modalities have been suggested by different authors, including drugs, prisms, botulinum toxin and surgery. The most popular surgical procedure is the Kestenbaum procedure, which is performed by recession and resection of the horizontal recti to carry the null zone to primary gaze in children who have a cosmetically offensive head position.

Another surgical procedure is symmetrical recession of the four horizontal rectus muscles. The precise mechanism underlying the beneficial effect of the symmetrical surgery is still controversial, although the results are obvious. By retroplacement of horizontal rectus muscle insertions behind the equator, posterior to the tangential point, the leverage is decreased and a given amount of muscle innervation will have less rotational effect on the globe. In cases of nystagmus, this will cause a decrease in amplitude. ${ }^{16}$ In another study, the authors suggested placement of a silicone encircling band around the globe over the four rectus muscles retroequatorially in nystagmus patients without a null point. Functionally the muscle was partially anchored to the sclera, creating a new anatomical insertion site with decreased action of muscles. ${ }^{22}$ Here, the aim is almost the same as with the horizontal recti recession operation; however, the surgical technique is different and the authors reported good results in only three patients.

The major criticism of this type of surgery was the concern of possible motility limitations after the operation, but this was previously shown not to be noticeable. Kushner et al. ${ }^{23}$ reported that recession of one or both medial recti posterior to the equator was a safe procedure, and with respect to mechanical factors, as much as $1.5 \mathrm{~mm}$ posterior to the equator can be used as the maximum recession point. ${ }^{23}$ Simultaneous recession of two antagonist rectus muscles does not change the balance between these muscles and causes very little limitation in motility without functional significance. In the Kestenbaum procedure the field of rotation of the eyes is also decreased in favour of correction of head posture, so mild motility limitation does not constitute a real disadvantage for this operation.

In all the patients in our study group surgery had a beneficial effect, except in one who had a decrease in VA after 12 months of follow-up even though she had better $\mathrm{VA}$ in the first and second follow-up visits. She also had peripheral pigmentation in the fundus examination as well as macular changes, suggesting hereditary degeneration. In patients with sensory nystagmus, the effect of surgery was not as good as in the congenital

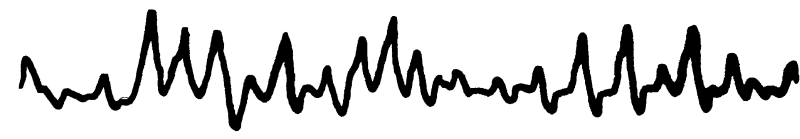

(a)

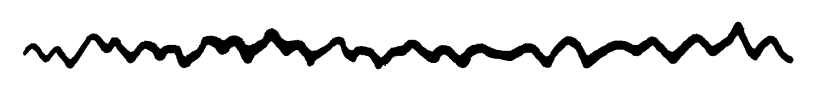

(b)

Fig. 1. Electronystagmographic recording of a patient (case 4) with congenital motor nystagmus pre-operatively (a) and post-operatively (b). 
motor nystagmus group. Partial improvement was seen that can be due partly to the elimination of the motor component of nystagmus.

In conclusion, we propose that symmetrical recession of the horizontal recti is a safe and effective procedure with a minimal decrease in ductions. The recession procedure is reversible and easier than the resection that is performed in the Kestenbaum operation. The symmetrical recession procedure is effective in decreasing the amplitude and frequency of nystagmus (Fig. 1). However, its effect on head posture is questionable. Further prospective studies with patients who have significant head posture are needed to compare the results of Kestenbaum or modified/ augmented Kestenbaum procedures with symmetrical horizontal rectus recessions.

\section{References}

1. Tychsen L. Pediatric ocular motility disorders of neuroophthalmic significance. Ophthalmol Clin North Am 1991;4:615-43.

2. Allen ED, Davies PD. Role of contact lenses in the management of congenital nystagmus. $\mathrm{Br} \mathrm{J}$ Ophthalmol 1983;67:834-6.

3. Barton JJS, Huaman AG, Sharpe JA. Muscarinic antagonists in the treatment of acquired pendular and downbeat nystagmus: a double-blind, randomized trial of three intravenous drugs. Ann Neurol 1994;35:319-25.

4. Ruben ST, Lee JP, O'Neil D, Dunlop I, Elston JS. The use of botulinum toxin for treatment of acquired nystagmus and oscillopsia. Ophthalmology 1994;101:783-7.

5. Helveston EM, Pogrebniak AE. Treatment of acquired nystagmus with botulinum A toxin. Am J Ophthalmol 1988;106:584-6.

6. Leigh RJ, Tomsak RL, Grant MP, Remler BF, Yaniglos SS, et al. Effectiveness of botulinum toxin administered to abolish acquired nystagmus. Ann Neurol 1992;32:633-42.
7. Leigh RJ, Burnstine TH, Ruff RL, Kasmer RJ. Effect of anticholinergic agents upon acquired nystagmus: a doubleblind study of trihexyphenidyl and tridihexethyl chloride. Neurology 1991;41:1737-41.

8. Carlow TJ. Medical treatment of nystagmus and ocular motor disorders. Int Ophthalmol Clin 1986;26:251-64.

9. Mitchell PR, Wheeler MB, Parks MM. Kestenbaum surgical procedure for torticollis secondary to congenital nystagmus. J Pediatr Ophthalmol Strabis 1987;24:87-93.

10. Abadi RV, Whittle J. Surgery and compensatory head postures in congenital nystagmus: a longitudinal study. Arch Ophthalmol 1992;110:632-5.

11. Lee JP. Surgical management of nystagmus. Eye 1988;2:44-7.

12. de Decker W. Kestenbaum transposition in nystagmus therapy. Bull Soc Belge Ophtalmol 1987;221/222:107-20.

13. Harcourt B. Faden operation (posterior fixation sutures). Eye 1988;2:36-40.

14. Scott WE, Kraft SP. Surgical treatment of compensatory head position in congenital nystagmus. J Pediatr Ophthalmol Strabismus 1984;21:85-95.

15. Biglan AW, Hiles DA, Ying-Fen Z, Kortvelesy JS, Pettapiece MC. Results after surgery for null point nystagmus with abnormal head position. Am Orthoptic J 1989;39:134-42.

16. von Noorden GK, Sprunger DT. Large rectus muscle recessions for the treatment of congenital nystagmus. Arch Ophthalmol 1991;109:221-4.

17. Helveston EM, Ellis FD, Plager DA. Large recession of the horizontal recti for treatment of nystagmus. Ophthalmology 1991;98:1302-5

18. Casteel I, Harris CM, Shawkat F, Taylor D. Nystagmus in infancy. Br J Ophthalmol 1992;76:434-7.

19. McCarty JW, Demer JL, Hovis LA, Nuwer MR. Ocular motility anomalies in developmental misdirection of the optic chiasm. Am J Ophthalmol 1992;113:86-95.

20. Weiss AH, Biersdorf WR. Visual sensory disorders in congenital nystagmus. Ophthalmology 1989;96:517-23.

21. Speirer A. Etiology of reduced visual acuity in congenital nystagmus. Ann Ophthalmol 1991;23:393-7.

22. Fioretto M, Burtolo C, Fava GP. New surgical method for nystagmus without null point. Ophthalmologica 1991;203:180-3.

23. Kushner BJ, Fisher MR, Lucchese NJ, Morton GV. How far can a medial rectus safely be recessed? J Pediatr Ophthalmol Strabismus 1994;31:138-46. 